FRAUNHOFER UMSICHT

\title{
Early warning and planning system Development of an early warning and planning system for Pathways to sustainable energy
}

\subsection{Introduction}

$\mathrm{T}$ The Pathways to sustainable energy project (Pathways) focuses on the sustainable development of energy supply for the benefit of society in the UNECE region. The project defines three pillars of sustainable energy:

1. Energy security, in particular, the security of supply

2. Energy and environment, in particular, the environmental impact of energy supply and use

3. Energy for quality of life, in particular, to ensure that social and societal development is positive, and that economic growth generates prosperity

These pillars are considered over time periods of several decades in order to capture suitable time horizons associated with climate change, technology development and deployment and economic development.

\subsection{WHAT IS AN EARLY WARNING AND PLANNING SYSTEM?}

Early warning and planning systems are an important instrument in our society for the reliable and early detection of undesirable developments or sudden and devastating events that disturb the planned development of countries. The system enables the more effective use of countermeasures and helps to minimize societal and financial losses.

In the past, early warning has been defined as "the set of capacities needed to generate and disseminate timely and meaningful warning information to enable individuals, communities and organizations threatened by a hazard to prepare and to act appropriately and in sufficient time to reduce the possibility of harm or loss" (UNISDR, 2009). This definition was also upheld by the IPCC (2012). "Early" signifies the time prior to the arrival of a hazard while there is still time to act upon and diminish the potential harm or loss. A "warning" is a communication protocol, a statement or event that warns of something or that serves as a cautionary example. A "system" is a standardized set of principles or procedures according to which something is done or an organized scheme or method. An end-to-end warning system

Blind peer reviews carried out

Mr. Fraunhofer Umsicht, UNECE Region, Suitzerland. is a complete set of components that connects those who need to hear messages to others who compile and track the hazard information of which messages are composed. Within these definitions, the task is to develop a set of procedures/ protocols that would take the information of an imminent "danger" and send it through a communication protocol to the end user. Another crucial point is that an early warning system needs a planning system to increase the awareness of policy makers and leaders. As such early warning and planning systems lead to a better understanding of socially complex systems and make policy responses more appropriate before disaster strikes by allowing preparations to counter any hazards before they occur. As Dwight D Eisenhower said in 1957, 'Plans are worthless but planning is everything'. By constantly being immersed in an issue, policy makers develop a 'feel' for the area which is invaluable in dealing with rapidly changing events.

Historically, many early warning and planning systems have been introduced to minimize the damage caused by natural disasters, for example, in the case of earthquakes $(\mathrm{Wu}$ und Kanamori 2008), tsunamis (Behrens et al. 2010) or volcanic eruptions (Rix et al. 2009), but there are also systems to warn of financial crises (Bussiere und Fratzscher 2006; Goldstein et al. 2000) or in the area of education (Macfadyen und Dawson 2010; Neild, Ruth Curran, Robert Balfanz, and Liza Herzog 2007). Crucially, these systems not only alert the population of an event but also indicate what immediate action should be taken.

At a global level, early warning and planning systems have also been established. The Montreal protocol, in 1987, foresaw the establishment of an implementation committee, supported by the Ozone Secretariat, tasked to monitor the targets on reducing ozone depleting substances. The nuclear non-proliferation treaty included an inspection regime that aims to identify attempts to develop nuclear weapons capabilities.

Recently, developments in energy sectors or energy supply are also monitored. For example, the European Union has implemented a monitoring system of the progress of the energy union (European Commission 2017). In the UK, the committee on climate change, established by statute, issues 
detailed monitoring reports on the UK government's climate change policy objectives and the likelihood that they will be achieved (committee on climate change 2018). Such 'monitoring systems' are usually not referred to as 'early warning and planning systems' as their horizon spans many years or decades and rarely indicate what corrective measures are required. but they form the basics of an early warning system if the urgency of response increases.

Regardless of the area of use, an early warning and planning system is generally a combination of 4 elements: human intelligence, supporting analytical tools, planning scenarios and a monitoring mechanism. Also, the desired output of an early warning system should be more than timely signals in case of an undesirable development. The likely cause of the problem and potential solutions should also be highlighted to enable timely control measures.

1.2 Why DEVELOP AN EARLY WARNING AND PLANNING SYSTEM FOR THE PATHWAYS to SUSTAINABLE ENERGY PROJECT?

Pathways to sustainable energy is not only influenced by the energy sector (the policies that concern the production, distribution and use of energy). It also considers the environment and climate change and so impacts other sectors (such as agriculture, forestry, urban development, water, etc.) as well as any social impacts.

This means that access or gathering of reliable data is not easy. Preferred sources of data come from an already established convention (such as The United Nations Framework Convention on Climate Change (UNFCCC)). These data inputs are in the form of Nationally Determined Contribution (NDC) submitted every 5 years under the Paris Agreement Article 4.9.

However, these contributions are not legally binding or enforced and only concern a part of the domain of Sustainable Energy. So, such data sources are valuable but have to be augmented with other sources. Additional data can be gathered from reports from other international organizations such as IEA, IRENA, etc. These valued sources can create problems to integrate their data in a consistent way. This applies to sources covering areas that are not energy-related such as the agricultural or social aspects of sustainable energy.

In order to analyze all this data sources for the purpose of an early warning system a hub is required that would receive, analyze and desegregate all information received from different sources and provide one streamlined resource on the basis of which certain indicators would trigger the early warning system.

This hub does not formally exist but a group using the updated integrated energy and climate models developed under the Pathways could provide a foundation for this function and extend the capability of the member countries.
For example, in the early stages of the Pathways project, several high-level scenarios were imagined to promote a policy discussion. These scenarios were based on 'high' and 'low' levels of innovation and cooperation.

It became clear that countries needed more specific scenarios such as

- If global warming accelerates and more rapid decarbonization is required, what options would I have to more quickly decarbonize and revise my NDCs?

- At what stage does a sub-region have to diversify from pipeline natural gas to LNG imports if Germany stops the use of coal by 20XX and switch to gas?

- If I wish to develop solar power, how important is the EU energy infrastructure vs energy storage for backup power?

- At what penetration of renewables should a country worry about competition for arable land use?

These questions illustrate:

1. The complicatedness of country goals: The goals in the Pathways projects are intended to be specific to each UNECE country and cover three areas (energy security, energy and the environment and energy and quality of life). These goals need to be combined in a standardized way to obtain an UNECE total

2. The complicatedness of the interactions between society, the environment and the energy system.

3. The complexity due to the fact that the challenges are fluent and dynamic. Goals may change with time, changes in one part of the system will have unforeseen and significant consequences across the rest of the system, and the timescales over which policies can act are very long and, therefore, subject to many unforeseen events.

4. The complexity that there are several ways to model interactions, these models are, necessarily, approximations and that these models evolve with time.

5. There are aspects of Pathways for which models may not be available, but which still need to be considered.

As such an early warning and planning system is important in Pathways. It is more efficient and understandable if answers for each of these specific questions draw off a consistent set of data and standardized models. Inevitable trade offs will be highlighted, long terms plans can be tracked with economic, environmental and social indicators and trigger points established as part of an early warning system. Combining country targets to identify synergies and dysynergies across regions becomes more feasible. Agreed regional indicators can be developed and quickly used to evaluate the impact of unforeseen events or deviations from overall plans. Deviations from the expected Pathways can be identified early and foster adaption of policies. 


\subsection{Background and purpose of the project}

The Pathways to sustainable energy project focuses on the sustainable development of energy supply (and demand) for the benefit of society. The project focuses on three pillars:

1. Energy security: in particular security of supply. This can relate to dependence on imports/sellers or dependence on a particular energy carrier, but also to the infrastructure or the costs to be incurred to secure supply.

2. Energy and environment: in particular at a sustainable, environmentally and climate-friendly development of energy supply. The focus is on energy consumption, energy efficiency, greenhouse gas emissions, technological progress and other environmental pollution caused by energy supply.

3. Energy for quality of life: in particular that social and societal development is positive, and that growth generates prosperity. This pillar focuses in particular on the energy supply of the population, the prosperity of the population or poverty within the population.

Given these three pillars, two integrated climate change models (Message of IIASA and GCAM of PNNL) have been completely updated to have greater granularity within the UNECE region.

These two models serve as the main modelling tools accessible to UNECE member states which are considering the assumptions and objectives of the member states for each of the three pillars, the models describe a pathway to the country targets in the form of social, economic and energy indicators. These indicators can form the numerical basis of an early warning and planning system.

The two models contain many indicators which countries are free to choose to use to monitor against their own targets.

At the level of the UNECE region, the selection of indicators is discussed in the next section.

\subsection{UNECE regional approach and methodology}

As described above, the early warning and planning system must continuously identify an undesirable development and be able to quickly evaluate the implications of sudden events. It is necessary to consider what appropriate data can be monitored in line with the Three Pillars in the Pathways Project.

The UN defines indicators as a suitable tool for a monitoring or early warning system. It says: "[Indicators] help incorporate physical and social science knowledge into decision-making, and they can help measure and calibrate progress toward sustainable development goals. They can provide an early warning to prevent economic, social and environmental setbacks. They are also useful tools to communicate ideas, thoughts and values" (United Nations 2007). The European Commission also uses indicators to monitor progress towards the objectives of the Energy Union (European Commission 2017). Since the developments to be monitored and the objectives to be achieved in the UNECE project are quite similar to those of the European Commission, the approach described below and the selection of indicators in section four are largely based on the approach of the European Commission but have been adapted for the Pathways project.

However, in contrast to the European Union approach, the UNECE aims to monitor both input and output indicators. Output indicators are the result of the model calculations. Input indicators and model assumptions determine the basis on which the scenarios are modelled and should affect any output indicators.

Moreover, indicators can be backward- and forwardlooking indicators. Backward-looking indicators are states of the economy and environment and more likely to be model outputs, for example the share of renewable energy or the $\mathrm{CO}_{2}$ emissions. Forward-looking indicators represent policies to meet the targets of backward-looking indicators. For example, forward indicators on policies to decarbonize the transportation sector might be tax relief on electric or fuel cell vehicles, rate of construction of charging infrastructure, investments in biofuels, etc. These would be expected to impact on the output indicators such as ' $\mathrm{CO}_{2}$ emissions from transport', energy mix, and so on. Indicators eligible for an early warning and planning system must fulfil certain requirements. They must be relevant (i.e. provide information on the degree to which objectives have been achieved), the data should be readily available and timely, it must be compatible with the data in the models, and must be reliable for modelling purposes. In brief, modelling is like a sewage system - what you get out depends very much on what you put in.

\subsection{MONITORING THE QUALITY OF ASSUMPTIONS AND INPUT INDICATORS IN THE MODELLING}

Monitoring the quality of assumptions and input indicators ensures the robustness of the model results. This avoids the risk that a measured deviation from the desired path is based on incorrect model results and not on an actual undesirable development is thus reduced.

This type of monitoring allows unexpected developments to be detected very early. For example, assumptions may have been made in the model about the level of investment in renewable energy. If the monitoring finds that the actual level of investment was significantly lower, an alarm is triggered. This case does not yet mean that the objectives, e.g. share of renewables in energy supply, cannot be achieved due to the lower level of investment, as development costs may have fallen more than expected or a breakthrough may have been achieved earlier than expected. However, if these development breakthroughs did not happen, a lower 
investment volume would lead to the objectives not being achieved.

This is better than an early warning system based only on output indicators. That would detect this increased risk much later when under-investment has led to a lower share of renewable energy or to lower efficiency of renewable energy. More specifically, an early warning system without assumptions and input indicator monitoring would only trigger an alarm when the effects become visible, which may take several years.

Due to the fact that assumptions and input indicators are so important, they are based on officially identified objectives or assumptions about the future. These objectives and assumptions, or a combination of these, are included in the models as input indicators or assumptions. For example, an official target could be a certain investment volume in renewable energies. Given an official assumption/forecast of GDP, this could result in an input indicator of investment volume in renewable energy per GDP. This indicator is based only on official assumptions and targets and is therefore completely independent of model results. Should the world develop differently than desired or expected, the early warning system triggers an alarm independent of the underlying models of the project.

The early warning system measures the difference between the input indicator originally included in the model and the values actually observed in reality. In the event of a significant deviation of an indicator, an alarm is triggered. More precisely, it measures how the development is progressing compared to how it was thought to be progressing, given the targets.

\subsection{OUTPUT INDICATOR MONITORING}

In contrast to the monitoring of input indicators or assumptions, the reliability of output indicators depends very much on the quality of the model which will always be some approximation to reality. In this case, indicators based on model results of certain scenarios are compared to the respective indicators based on real data, highlighting if the difference is regarded as excessive.

An advantage of this method is that the Pathways described by the models do not only provide values for a target in the distant future, but also intermediate, annual target values are available and thus a continuous monitoring of developments is possible.

Furthermore, it does not monitor assumptions or prerequisites that lead to the achievement of targets, but rather the actual degree to which targets have been achieved, which makes it possible to make more substantiated statements about necessary measures.

A disadvantage of this method, however, as described above, are the time lags, that only undesirable developments are identified (rather than the causes that lead to these undesirable developments). Another disadvantage is, of course, the model dependency and the uncertainty or risk that the model results become obsolete.

\subsection{Selection of UNECE indicators to monitor progress in the Pathways project}

The following indicators have been selected as candidates to monitor progress at the UNECE regional level towards sustainable energy.

\subsection{ASSUMPTION AND INPUT INDICATORS}

SSP2 related

- Population growth per region: The rate at which the population grows in each region.

- GDP growth per region: The rate at which the gross domestic product grows in each region.

- GDP growth per sector: The rate at which the gross domestic product grows in each sector of the economy.

- Urbanization: The rate at which people move from rural to urban areas.

- Availability of raw materials: Details the supply curve of raw materials, for example oil.

\section{Technology related}

- Capital cost: The development of capital costs of energy technologies over time.

- Operation and maintenance cost: The development of operation and maintenance costs of energy technologies over time.

- Conversion efficiency: The development of the conversion efficiency of energy technologies.

- Lifetime: The development of lifetimes of energy technologies.

Policy related

- Rate of building renovation: The rate at which the energy efficiency of buildings is increased.

- Public investment: The level of public investment into technologies or other projects. This indicator can have multiple forms.

- Carbon policy: The availability of a carbon trading system or a carbon price.

- Subsidies: Prioritization of certain technologies or activities through reduced levies.

\subsection{OUTPUT INDICATORS}

As with the input indicators and the assumptions, the output indicators are classified under the three pillars of the project. Within the pillars, the indicators are clustered again in groups. The list of indicators presented is only a sample

${ }^{1}$ https://secure.iiasa.ac.at/web-apps/ene/SspDb

dsd? Action $=$ htmlpage $\&$ page $=$ about 
and needs to be developed individually for each country based on the circumstances and availability of model and real data.

\subsubsection{Energy security}

Import dependency

Imports of energy play a central role in some countries and in some cases security of supply can only be ensured through imports. Political tensions with the selling countries or conflicts in the selling countries can threaten security of supply. For this reason, a high degree of independence with regard to energy imports is an indicator of more stable security of supply.

- Energy imports in \%: This indicator measures total energy imports in a common unit. (Indicator developed during the project)

- Net import dependency: This indicator measures the level of total net imports as a proportion of total gross inland consumption. More detailed levels of this indicator are net import dependency by energy carrier (gas, oil, coal, nuclear). (European Commission 2017)

Imports and exports by country of origin

Since energy imports alone provide information on how much energy is imported from abroad, but do not include the degree of dependence on individual selling countries, it is also worth looking at the concentration of suppliers. To be more precise, how strong the dependency on only one or very few suppliers is. A lower concentration therefore means less dependence and more security.

- Aggregate supplier concentration: This indicator measures the importance of total imports of main energy carriers to a Member State from suppliers. More detailed levels are supplier concentration by fuel. (European Commission 2017)

Fuel Mix

Not only the dependence on a few suppliers, but also the dependence on a certain fuel increase the risk of supply failures. For example, price shocks or supply bottlenecks, but also in terms of renewable energy, wind slack or heavy cloud cover, can affect supply if a Member State is too dependent on individual energy sources.

- Shares of the individual energy sources in the energy supply: This indicator measures the energy supply of member states by energy carrier in per cent. (Indicator developed during the project)

Infrastructure

Infrastructure is also an important component in terms of security of supply. A deteriorating infrastructure can endanger the supply of individual regions or the entire country and requires constant investment in maintenance.

- Expected energy non-served in GWh/year: This indicator measures the expected amount of energy not being served to consumers by the system during a year due to system capacity shortages or unexpected severe power outages. (European Commission 2017)

- Loss of load expectation in hours/year: This indicator represents the number of hours per year in which it is expected that supply will not meet demand.(European Commission 2017)

- Energy reliability: This indicator is composed of the following sub-indicators: Vintage of infrastructure, reserve margins, storage capacities, and interconnections to neighboring regions. (Indicator developed during the project)

- Supply security in \%: This indicator measures the addition of new generation equipment, including RE. (Indicator developed during the project)

- Losses of energy in mains and grids in \%: This indicator measures the energy lost through the grid in GWh and in per cent. (Indicator developed during the project)

- Investment requirements in \$: This indicator measures the volume of investment required in infrastructure per year. (Indicator developed during the project)

ENERGY COSTS

An important factor in energy security is the cost of energy. If these costs are too high, energy is no longer affordable for people and the security of supply is endangered.

- Primary energy prices by fuel in $\$ / G J$ : This indicator measures primary energy prices by fuel. (Indicator developed during the project)

- Final energy prices by fuel in $\$ / G J$ : This indicator measures final energy prices by fuel. (Indicator developed during the project)

- Energy expenditures in $\$$ : This indicator measures energy expenditures by multiplying consumption and prices. (Indicator developed during the project)

- Energy expenditures per capita in \$: This indicator measures energy expenditures per capita by dividing energy expenditure per capita. (Indicator developed during the project)

- Energy expenditures per GDP in \$: This indicator measures energy expenditures per GDP by dividing energy expenditure by GDP. (Indicator developed during the project)

\subsubsection{Energy and environment}

Primary energy demand

Primary energy can be provided by both fossil and renewable energy sources. In particular, the combustion of coal, natural gas and oil are among the main sources of greenhouse gas emissions. Against this background, the 
origin and composition of primary energy in a country is of crucial importance for sustainable development of the energy sector.

- Primary energy consumption in GJ: This indicator monitors changes in primary energy consumption. A more detailed variant would be primary energy consumption by energy carrier. (European Commission 2017)

- Primary energy intensity: This indicator is defined as primary energy consumption divided by GDP. It thus provides information on the potential decoupling of economic growth and energy consumption. (European Commission 2017)

- Carbon intensity of fossil energy in $\mathrm{CO}_{2}$ /unit fossil energy: This indicator measures the average carbon content of a unit of energy. Thus, a mean is formed from all energy sources and their shares in energy consumption. (Indicator developed during the project)

- Fossil share in energy in \%: This indicator shows the share of fossil fuels in primary energy consumption. (Indicator developed during the project)

Final energy demand

The demand for final energy shows the prosperity of a society on the one hand, but also the efficiency of the sectors that use the energy on the other hand, if one relates them to other values. In addition, the demand for final energy has a direct influence on the demand for primary energy and is therefore a main driver of emissions.

- Final energy intensity by sector in $\mathrm{J} / \$$ : This indicator is calculated by dividing the sectors' final energy consumption by their total gross value added. Reducing final energy intensity means to decouple industrial growth from energy consumption. The lower the value, the more energy-efficient the sector is. (SDG 7 (7.3.1))

- Final energy consumption per square meter in residential sector in $\mathrm{J} / \mathrm{m}^{2}$, climate corrected: This indicator measures energy consumption per square meter of living space in residential buildings. The indicator is climate-adjusted so that long-term trends can be identified that are not distorted by strong winters. The indicator shows the energy efficiency of the building stock; the lower it is, the higher will be the efficiency. (European Commission 2017)

- Final energy consumption in transport in GJ: The indicator shows the energy consumption of the transport sector. Further information such as average kilometers per person and average kilometers per tonne of freight can be used to calculate energy consumption per passenger kilometer or per tonne kilometer, indicating the efficiency of the sector. (European Commission 2017)

- $\mathrm{CO}_{2}$ emissions of new cars: The indicator shows the $\mathrm{CO}_{2}$ emissions of new cars and can thus indicate the progress of decarburization in the sector. (European Commission 2017)
- Share of alternative fuel vehicle in \%: This indicator also shows the decarburization progress of the transport sector. (Indicator developed during the project)

- Infrastructure of alternative fuel vehicle: This indicator shows the infrastructure improvements of the various alternative fuel vehicle. It is therefore also an indicator of the attractiveness of such vehicles for end customers. In order to get values, an evaluation system for the infrastructure has to be developed. (Indicator developed during the project)

\section{Energy efficiency}

Increasing energy efficiency helps to reduce the demand for energy or at least to prevent it from rising further as prosperity increases. Increasing energy efficiency can thus make a major contribution to phasing out fossil primary energy sources.

- Investments in energy efficiency as a percentage of GDP: This indicator shows how much of the gross domestic product is invested in measures to increase energy efficiency. The advantage of the indicator is that it shows undesirable developments at an early stage and not their effects on emissions. (SDG 7 (7.B.1))

\section{GHG emissions}

Greenhouse gas emissions and the proportion of greenhouse gases in the air are the main causes of climate change. The Paris climate targets can only be achieved by reducing them. Indicators based on greenhouse gases are therefore an important component of the early warning system.

- $\mathrm{GHG}$ emissions by sector in $\mathrm{tCO}_{2}$ : This indicator measures greenhouse gas emissions by sector of the economy and thus shows which sectors should be prioritized for reduction measures. (Indicator developed during the project)

- LULUCF emissions in $\mathrm{tCO}_{2}$ : This indicator indicates the level of emissions from land use, land-use change and forestry. Negative emissions can also be achieved through afforestation. (Indicator developed during the project)

- $\mathrm{GHG}$ emissions per capita in $\mathrm{tCO}_{2}$ : The indicator shows greenhouse gas emissions per capita and is thus an indicator independent of population size and can serve as a good comparative value to other countries. (European Commission 2017)

- GHG intensity of economy in $\mathrm{tCO}_{2} / \$$ : This indicator relates emissions to gross domestic product. The lower the value is, the lower will be the carbon intensity of the economy. (Indicator developed during the project)

- GHG intensity of power and heat sector $\mathrm{CO}_{2} / \mathrm{MWh}$ : The indicator measures the power and heat generated in relation to gross value added. As the power and heating sector is usually the most emission-intensive sector of an 
economy, the indicator is important, especially to monitor the desired decoupling of growth and emissions in this sector. (European Commission 2017)

\section{Technology}

The development of new technologies or the improvement of existing technologies are of central importance for the achievement of climate targets or sustainable development. For example, alternative emission-free technologies for energy generation or new technologies for storing $\mathrm{CO}_{2}$ must be developed, or existing technologies in these areas must become more efficient and cost-effective to achieve the targets. These necessary innovations will increase the market penetration of emission-free technologies and thus make a major contribution to achieving climate targets costeffectively.

- Renewable energy share in the total final energy consumption in \%: The indicator measures the share of renewable energies in energy consumption and thus monitors the decarburization progress of the energy sector. (SDG 7 (7.2.1))

- Conversion efficiency in \%: This indicator measures the average conversion efficiency of electricity generation. (Indicator developed during the project)

Environmental pollution

Sustainable development is not limited to greenhouse gas emissions, but other environmental factors such as water, particulate matter or waste also play a role.

- Pollution by non-GHG in $\mu \mathrm{g} / \mathrm{m}^{3}$ or $\mathrm{ppm}$ : This indicator measures pollution from non-greenhouse gases. (Indicator developed during the project)

- Water depletion/replenishment in $\mathrm{km}^{3} / \mathrm{yr}$ : The indicator measures the relationship between water abstraction and water supply. The natural water reservoirs are considered. A depletion that exceeds the replenishment means unsustainable management. (Indicator developed during the project)

- Water deficit (demand/supply relation): The indicator measures the relationship between demand and supply of water. Demand that exceeds supply increases the risk of exploitation of natural water resources. (Indicator developed during the project)

- Waste disposal in \%: The indicator measures the proportion of urban solid waste regularly collected and with adequate final discharge out of total urban solid waste. A higher proportion means less pollution from, for example, plastics. (SDG 11 (11.6.1))

- Particulate matter indicator in days: Number of days per year on which the particulate matter limits in cities are exceeded. (Indicator developed during the project)

- Public investments in necessary low carbon technologies in $\$$ : The indicator monitors public investment necessary to achieve certain objectives. (Indicator developed during the project)

- Land cover in \%: Thousand hectares forest or other protected lands in relation to total land area. (Indicator developed during the project)

- Global average temperature change in ${ }^{\circ} \mathrm{C}$ : The indicator measures the temperature increase compared to preindustrialization and thus shows how far climate change has progressed in a particular region. (Indicator developed during the project)

- Mineral resource use or fossil energy resource use: For the use of mineral resources or fossil energy sources to generate electricity, mining areas are needed, which in turn means a massive destructive intervention in nature. The indicator therefore shows how carefully resources are used. (Indicator developed during the project)

\subsubsection{Energy for quality of life}

Energy

Energy is needed for almost all goods and commodities as well as for the transport of goods. Energy is also consumed in private households, for example for heating, cooking or lighting. An affordable energy supply therefore plays a central role in the development and prosperity of a society.

- People with access to energy in \%: The indicator shows the percentage of the population with access to energy. It is thus an important indicator of economic and social development. (Indicator developed during the project)

- Households connected to the grid in \%: The indicator shows the percentage of households connected to the electricity grid. It is therefore an important indicator for the expansion of the infrastructure and the structural development of the country. (Indicator developed during the project)

- Energy services per capita, absolute and efficiency adjusted J/capita/year: The indicator measures how much energy services per capita have been consumed in one year. The higher the indicator is, the higher is the quality of life. (Indicator developed during the project)

- Energy expenditure share in final consumption in \%: The indicator measures what percentage of total expenditure in a society is spent on energy. The lower the percentage is, the more money is available for other consumption of goods and the higher will be the quality of life. (European Commission 2017)

OTHER

In addition to energy, other important indicators are central to the quality of life and sustainable development of a society. In particular, the supply of food plays a central role.

- GDP per capita in \$: Gross domestic product per capita as a common indicator for measuring a country's level of development. (Indicator developed during the project) 
- Share of population at risk of hunger in \%: This indicator measures the percentage of people potentially affected by the risk of hunger. The lower the percentage is, the higher is the quality of life. (Indicator developed during the project)

- Share of calories from staple food in \%: A high value of the indicator means that people can only afford basic food and accordingly many people are at risk of not being able to provide themselves with enough food. (Indicator developed during the project)

- Food security in \%: The indicator represents a value of food consumption multiplied by prices and divided by GDP. It therefore shows the share of food expenditure in total GDP. The higher the value is, the lower will be the quality of life. (Indicator developed during the project)

- Pollution related deaths: The indicator measures deaths caused by environmental pollution in relation to all deaths in a country. This means deaths from gases, particulate matter, nuclear radiation, liquid or solid poisons or other pollution. The higher the value is, the lower is the quality of life. (Indicator developed during the project)

\section{Overview of an early warning and planning system}

This paper has highlighted the important aspect of the early warning and planning system including those specific to Adaptive Policy Pathways for Sustainable Energy. This requires an iterative process (Fig.1) which can have benefits for more than sustainable energy (such as exploring the types of questions posed in the Introduction).

Sustainable energy policies affect the global economy and environment, not just the UNECE region. These global changes can be tracked and incorporated in the model making the regional monitoring process more realistic and relevant. Any deviations can lead to a revision of the initial targets and the adjustment of sustainable energy aims. The sustainable energy targets and updated input assumptions can then be used to model adaptive Pathways towards these targets. Insights from the modelling activity can then be used to aid the policy design with the latest information.

Given a suitable organization, this process can become iterative. It is estimated that this process would have to be repeated every couple of years to allow enough time for the policy to produce notable results and changes in the global system to be incorporated.

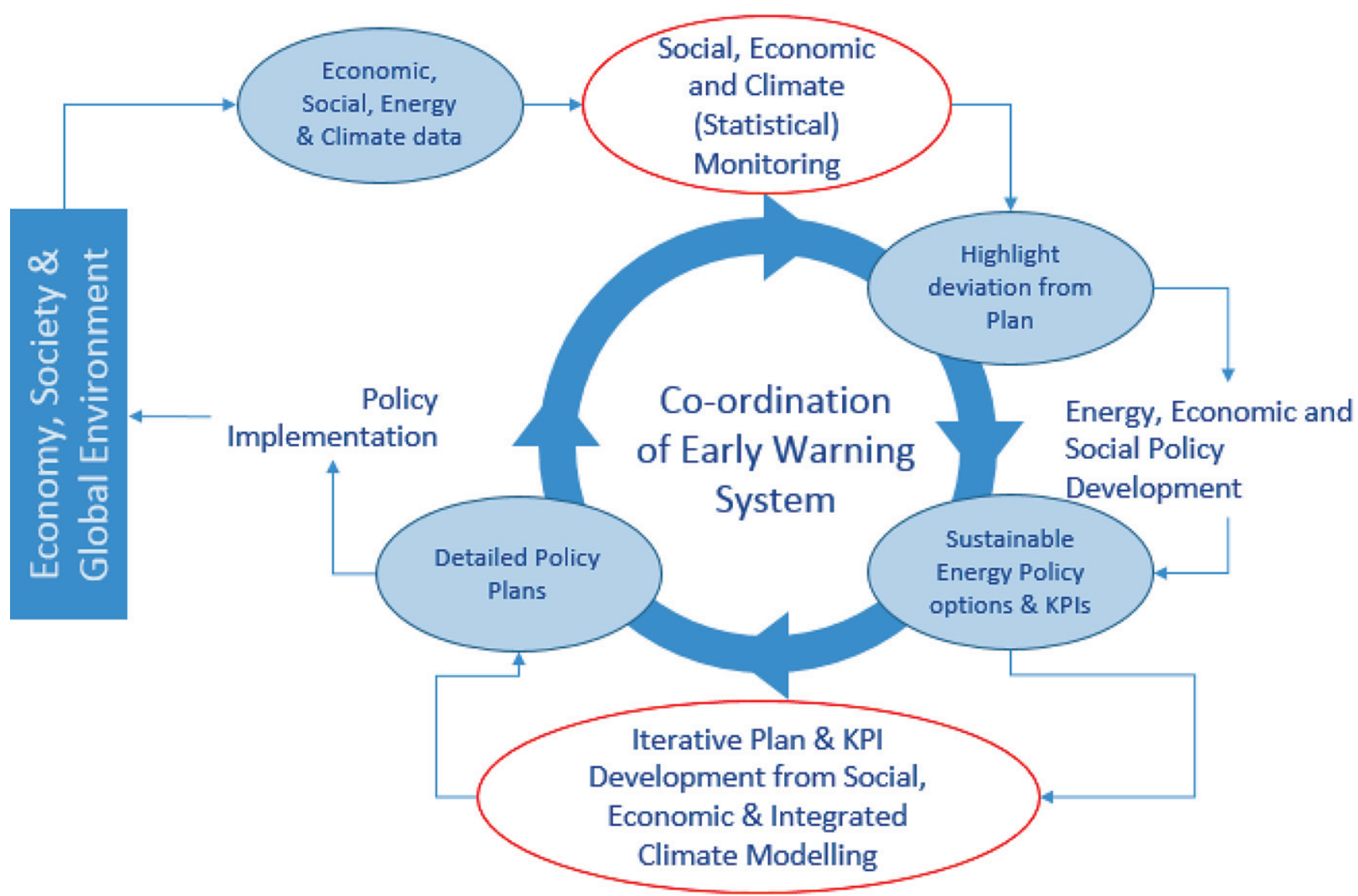

Fig.1: Elements of an early warning and planning system highlighting the role of indicators and modelling 
The overall concept facilitates the use of scenarios to show how and by which methods and indicators unforeseen and undesirable developments can be identified early and reliably.

In addition, the approach allows the development of an understanding of the likely origins of the undesirable developments, allowing rapid intervention in the sectors concerned. Different technology or policy scenarios can be run. These may or may not achieve the sustainable energy targets (for example the 2-degree target). For each scenario a trigger/tipping point should be included, for example the percentage of the carbon budget used up, after which the current path must be left or adjusted in order to reach the goal. Moreover, each scenario will likely have important assumptions that need to be fulfilled for it to be a realistic option. These assumptions can be the determining factor should a region or country reach a crossroad point between scenarios that both have the potential to reach the sustainable energy target. An example could be the focus on

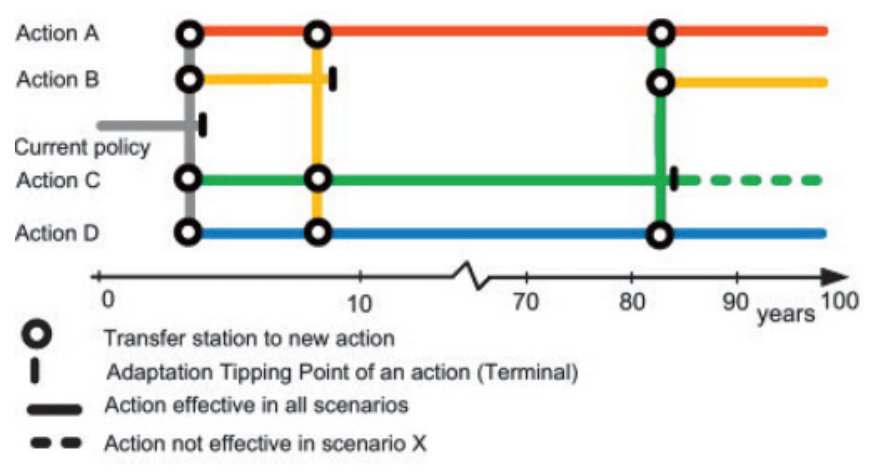

\section{Adaptation Pathways Map}

Fig.2: An example of an adaptation Pathways map. Different actions represent different policy and technology scenarios that may or may not (action C) reach a predefined target (Haasnoot et al. 2013) gas technologies versus renewable technologies. A switch to renewables may be favorable if by that time adequate and cost-effective storage technologies are available, or the price of renewables has decreased even further. On the other hand, staying on the gas path may only be feasible if the price of carbon capture technologies reaches a certain level. After a variety of scenarios are modelled the insights from this activity can be used to create an adaptive pathway map like the one as is shown in Fig. 2.

For this activity to be successful there need to be quantifiable targets for all of the sustainable energy pillars. In addition, potential crossroads need to be clearly defined and the scenarios must be designed to be distinct enough.

In Fig. 1 the two areas where this project plays a role are also highlighted in red ellipses. Selecting relevant indicators to monitor and modelling Pathways based on sustainable energy targets.

This Early Warning System uses a two-layered approach. The first, and most important, layer is that of the Member State. The second is that of the UNECE region which is simply a summation of the individual country inputs created in a standardized format by using the same Integrated Energy and Climate Models.

It is important to note that e Member States can consider other areas in their modelling beyond those developed for the Three Pillars (Fig.3).

Although it is possible to use different models than Message and GCAM used in Pathways, there are advantageous related to keeping them. They can be tailored to not only model the world or UNECE region as whole but also specific (sub-) regions. This requires the provision of sufficient information on the region. Moreover, both models are open source and (after capacity building) can be applied by member states.

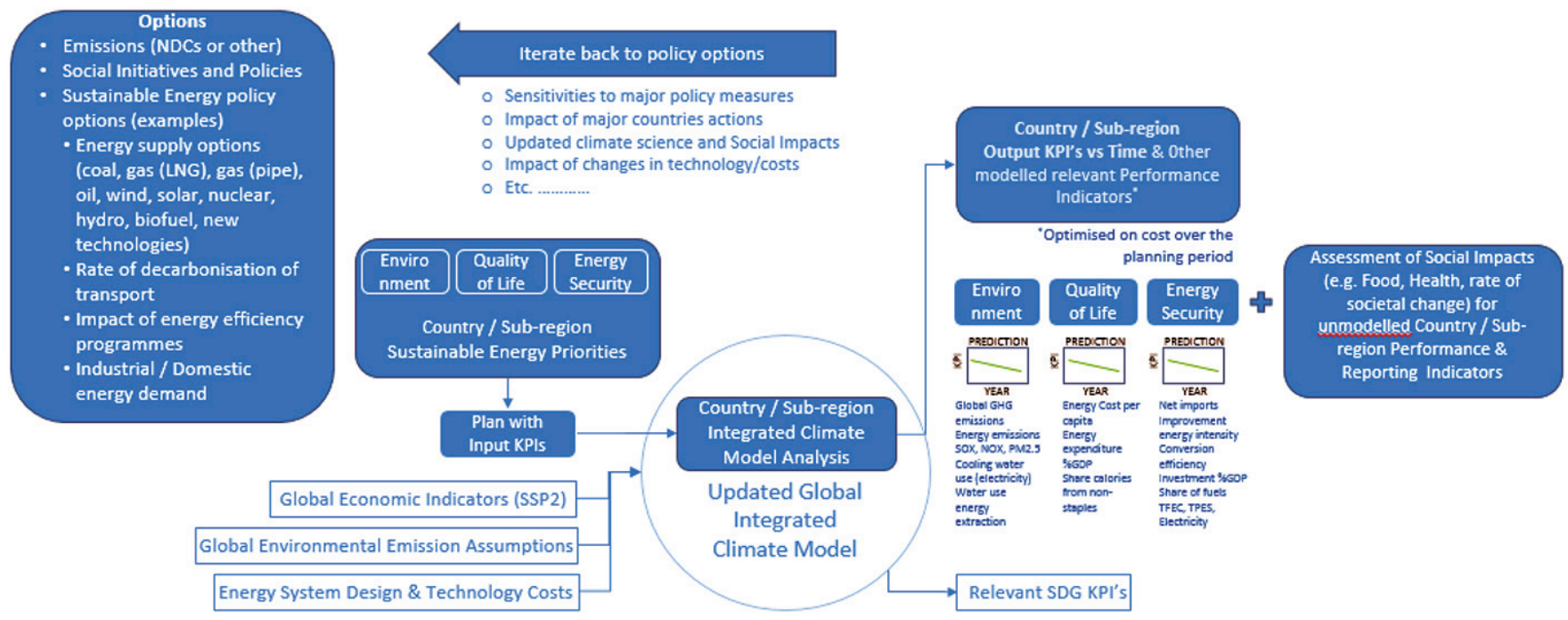

Fig.3: National level early warning system 


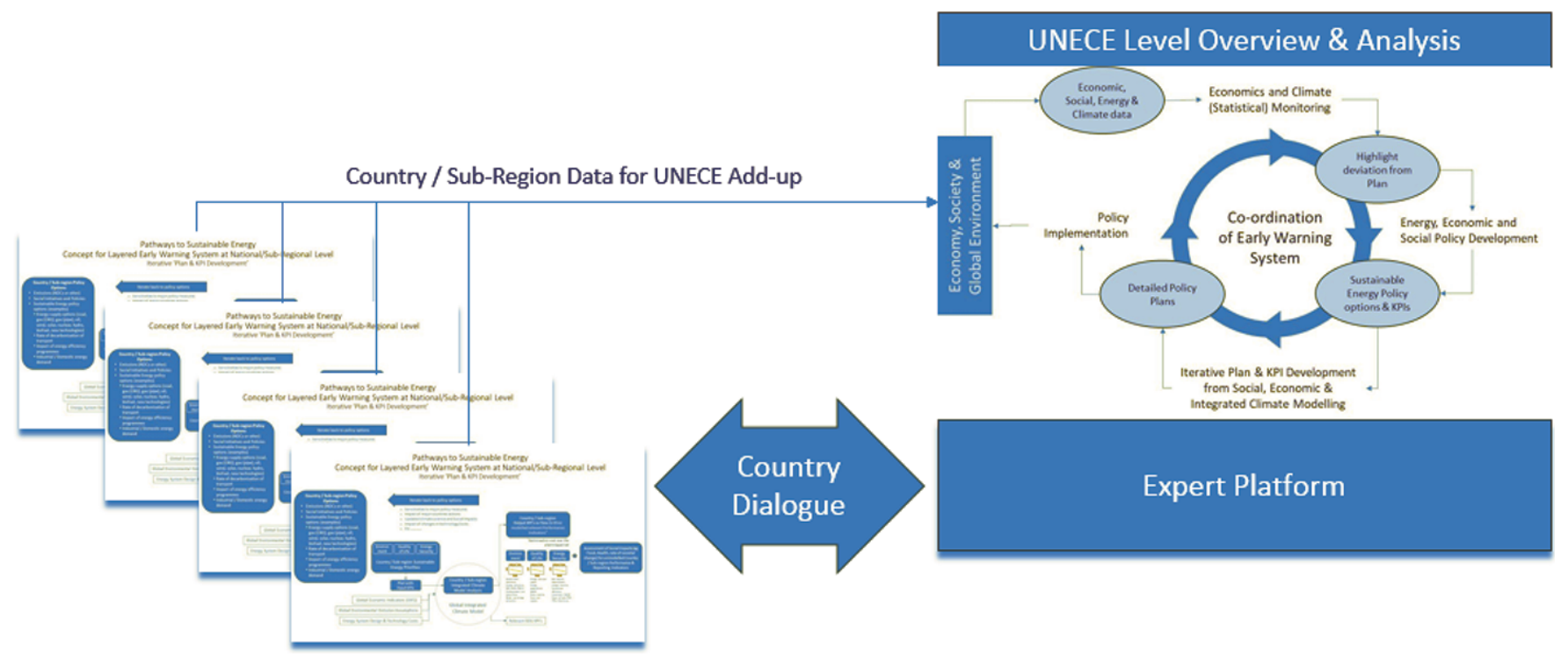

Fig.4: Concept for layered Early Warning System at Regional Level

If the same models are used, these national models can be 'summed up' to compile a UNECE level Early Warning System based on the indicators used for the Three Pillars of Sustainable Energy. This also facilitates the introduction of an expert interface to promote a dialogue and help with the execution of the models. The dialogue would encourage co-operation and help identify synergies across the UNECE region.

Since any system at the country level will not be operated by the UNECE but will be the responsibility of the individual member states, it remains the responsibility of the member states to adapt and implement the early warning system in such a way that it can best perform its task, given the particularities and objectives of the country. This is where the expert interface may play a crucial role. Some of the indicators listed here may not be included in the individual systems at a later stage, other indicators may be included which are not in this concept. Furthermore, the usability of the indicators also depends on the availability of data, as these vary widely between member states and the models differ in terms of the available indicators, the developed concept can be seen more as a framework than a fully developed system for a member state.

The question as to when a measured deviation triggers an alarm must also be worked out in the respective member state, since this question depends on the selection but also the prioritization of the indicators. These two points are strongly driven by the individual conditions and the individual targets of each country. For this reason, when implementing this concept, the member states should therefore define the conditions under which an alarm is triggered. There can be different approaches to this. For example, a certain percentage deviation or a certain absolute deviation of an indicator could trigger an alarm, whereby these values could in turn be defined individually for each indicator. However, it could also be that only a combination of different indicators can trigger an alarm, or that if different very similar indicators deviate in the same direction, the threshold from which an alarm is triggered is lower than in the case where only one indicator deviates. The threshold value could also be lower for a continuous deviation in the same direction than for a single deviation. A concept of when an alarm is triggered remains, however, for the reasons given above, the responsibility of member state wanting to implement the early warning system.

As discussed above, under the given conditions, the concept of an early warning system developed provides a framework that can be applied. However, due to the peculiarities of the countries, they must develop the exact design themselves.

\subsection{Conclusions}

The Pathways project has resulted in the development of a more detailed and more comprehensive model of the UNECE Climate and Energy System.

This model is available for countries to model their own situation.

Three pillars of sustainable energy have been defined that can be used at a country, sub-regional and regional level to track progress towards sustainable energy. These pillars do not limit countries in the development of their own indicators of sustainable energy. The Pillars can be defined by a small subset of indicators which are useful to track progress towards sustainable energy.

Easy access to the models allows them to be used as tools in policy formation and monitoring of progress. As time progresses, the models can be used to quickly re-evaluate policies, thereby increasing the effectiveness of adaptive policy Pathways. 
If countries adopt the methodology of using the sustainable energy approach in combination with the developed models, they will have several advantages: access to the latest, most refined integrated climate and energy models, participation in an expert platform that can be used to model their own country's progress to sustainable energy with relevant information on other countries activities as modelled, and facilitation of a UNECE overview of progress towards sustainable energy.

\subsection{Recommendations for further developments with the Pathways project}

The Pathways project has enabled the development of a tailored, integrated energy and climate change model for the UNECE with updated technology profiles. This model is being successfully used to analyze adaptive policy Pathways within the sustainable energy community. Pathways can be used to facilitate the use of these tools by Members for their policy developments. This common approach also provides a common platform to provide a consistent UNECE level overview to enrich the sustainable energy debate amongst Member States seeking areas of cooperation and synergy. It is therefore proposed to extend the Pathways project to catalyse such an energy debate.

The Pathways project has resulted in an energy system model which is well respected for its energy and climate modelling covering the pillars of environment and energy security. In the areas of quality of life, there are many gaps in the social aspects of sustainable energy which should be incorporated into the adaptive policy Pathways. It would be useful to expand the use of the models to explore the impacts of sustainable energy and climate change on changes in public health (movement of human disease and parasites), food (changes in productivity due to climate change, migration of parasites and water supplies), changes in employment as the circular economy evolves and other aspects of social change. The initial aim would be to catalogue and profile the major impacts that policy makers should consider.

Given that the generation and supply of electricity by renewable and lower carbon energy is largely underway, use the Pathways project to look forward to the more technically and socially complex challenge of liquid fuels and integrating these into the technology options for mitigating climate change and the energy transition.

Given that the modelling indicates that meeting the $2 \mathrm{C}$ is increasingly difficult given the requirement for many complex and simultaneous transitions, extend the technology mapping to inform policy makers of emerging technologies aimed at mitigating climate change which will be necessary after the 2050 watershed when emissions reduction will become increasingly more difficult.

\subsection{References}

1. Behrens, J.; Androsov, A.; Babeyko, A. Y.; Harig, S.; Klaschka, F.; Mentrup, L. (2010): A new multi-sensor approach to simulation assisted tsunami early warning. In: Nat. Hazards Earth Syst. Sci. 10 (6), S. 1085-1100. DOI: 10.5194/nhess-10-1085-2010.

2. Bussiere, Matthieu; Fratzscher, Marcel (2006): Towards a new early warning system of financial crises. In: Journal of International Money and Finance 25(6), S. 953-973. DOI: 10.1016/ j.jimonfin.2006.07.007.

3. European Commission (2017): Second Report on the State of the Energy Union. Monitoring progress towards the Energy Union objectives - key indicators. In: Commission Staff Working Document 2017.

4. Goldstein, Morris; Reinhart, Carmen M.; Kaminsky, Graciela Laura (2000): Assessing financial vulnerability. An early warning system for emerging markets. Washington, DC: Institute for International Economics. Online verfügbar unter http:// lib.myilibrary.com/detail.asp?id=204072.

5. Haasnoot, Marjolijn; Kwakkel, Jan H.; Walker, Warren E.; ter Maat, Judith (2013): Dynamic adaptive policy Pathways. A method for crafting robust decisions for a deeply uncertain world. In: Global Environmental Change 23 (2), S. 485-498. DOI: 10.1016/ j.gloenvcha.2012.12.006.

6. Macfadyen, Leah P.; Dawson, Shane (2010): Mining LMS data to develop an "early warning system" for educators. A proof of concept. In: Computers \& Education 54 (2), S. 588-599. DOI: 10.1016/ j.compedu.2009.09.008.

7. Neild, Ruth Curran, Robert Balfanz, and Liza Herzog (2007): An early warning system. In: Educational leadership 2007 (65(2)), S. 28-33, zuletzt geprüft am 07.12.2018.

8. Rix, Meike; Valks, Pieter; Hao, Nan; van Geffen, Jos; Clerbaux, Catherine; Clarisse, Lieven et al. (2009): Satellite Monitoring of Volcanic Sulfur Dioxide Emissions for Early Warning of Volcanic Hazards. In: IEEE J. Sel. Top. Appl. Earth Observations Remote Sensing 2 (3), S. 196-206. DOI: 10.1109/ JSTARS.2009.2031120.

9. United Nations (2007): Indicators of sustainable development. Guidelines and methodologies. 3. ed. New York: United Nations (Economic \& social affairs).

10. Wu, Yih-Min; Kanamori, Hiroo (2008): Development of an Earthquake Early Warning System Using Real-Time Strong Motion Signals. In: Sensors (Basel, Switzerland) 8 (1), S. 1-9. DOI: 10.3390/s8010001.

11. Reducing UK emissions - 2018 Progress Report to Parliament, Committee on Climate Change, 7 Holbein Place, London, SW1W 8NR, June 2018.

12. www.theccc.org.uk/publications 